\title{
Correction to: From Teachers' Work Engagement to Pupils' Positive Affect: a Weekly Diary Study on the Role of Pupils' Autonomous Motivation
}

\author{
Maja Tadić Vujčić ${ }^{1}$ (D) Eduardo Garcia-Garzon ${ }^{2}$ - Buse Gonul ${ }^{3} \cdot$ Irina Gioaba $^{4}$ \\ Published online: 20 March 2021 \\ (C) The International Society for Quality-of-Life Studies (ISQOLS) and Springer Nature B.V. 2021
}

\section{Correction to: Applied Research in Quality of Life https://doi.org/10.1007/s11482-021-09920-y}

The original version of the article unfortunately contained an error.

Author affiliations were inadvertently published in the wrong order and author e-mails were added with wrong domain names. The correct author affiliations and e-mails are shown above.

The original article has been corrected.

The online version of the original article can be found at https://doi.org/10.1007/s11482-021-09920-y

Maja Tadić Vujčić

maja.tadic@pilar.hr

Eduardo Garcia-Garzon

egarcia@ucjc.edu

Buse Gonul

buse.gonul@ogu.edu.tr

Irina Gioaba

irina.gioaba@unil.ch

1 Institute of Social Sciences Ivo Pilar, Zagreb, Croatia

2 Facultad de Salud, Universidad Camilo José Cela, Villafranca del Castillo, Madrid, Spain

3 Department of Psychology, Eskisehir Osmangazi University, Eskisehir, Turkey

4 Department of Organizational Behavior, University of Lausanne, Lausanne, Switzerland 